\title{
Factors Associated with Malignant Biliary Strictures in Patients with Atypical or Suspicious Cells on Brush Cytology
}

\author{
Ji Young Park and Tae Joo Jeon \\ Division of Gastroenterology, Department of Internal Medicine, Sanggye Paik Hospital, Inje University College of Medicine, Seoul, Korea
}

Background/Aims: Pathological diagnosis of biliary strictures with atypical or suspicious cells on endoscopic retrograde brush cytology and indeterminate strictures on imaging is challenging. The aim of this study was to identify markers for malignant strictures in such cases.

Methods: We retrospectively analyzed data collected from 146 consecutive patients with indeterminate biliary strictures on imaging who underwent endoscopic retrograde brush cytology from 2007 to 2013. Factors associated with malignant strictures in patients with atypical or suspicious cells on brush cytology were identified.

Results: Among the 67 patients with a malignant disease (48 cholangiocarcinoma, 6 gallbladder cancer, 5 pancreatic cancer, 5 ampulla of Vater cancer, and 3 other types), 36 (53.7\%) had atypical or suspicious cells on brush cytology. Among these, the factors that independently correlated with malignant strictures were stricture length (odds ratio [OR], 5.259; 95\% confidence interval [CI], 1.80215.294) and elevated carbohydrate antigen 19-9 (CA19-9) (OR, 3.492; 95\% CI, 1.242-9.815), carcinoembryonic antigen (CEA) (OR, 4.909; 95\% CI, 1.694-14.224), alkaline phosphatase (ALP) (OR, 3.362; 95\% CI, 1.207-9.361), and gamma-glutamyl transpeptidase (rGT) (OR, 4.318; 95\% CI, 1.512-12.262).

Conclusions: Elevated levels of CA19-9, CEA, ALP, and rGT and stricture length are associated with malignant strictures in patients with indeterminate biliary strictures on imaging and atypical or suspicious cells on brush cytology. Clin Endosc 2019;52:168-174

Key Words: Brush cytology; Biliary stricture; Atypical cell; Suspicious cell

\section{INTRODUCTION}

Biliary strictures are byproducts of benign and malignant diseases involving the biliary tree, pancreas, gallbladder, or ampulla. ${ }^{1-4}$ Accurate pathological diagnosis of biliary strictures remains clinically challenging, but is essential for choosing the correct treatment. ${ }^{4,5}$ As an alternative to biopsy, which is ham-

Received: June 15, 2018 Revised: August 25, 2018

Accepted: September 17, 2018

Correspondence: Tae Joo Jeon

Division of Gastroenterology, Department of Internal Medicine, Sanggye Paik Hospital, Inje University College of Medicine, Sanggye Paik Hospital, 1342 Dongil-ro, Nowon-gu, Seoul 01757, Korea

Tel: +82-10-5397-8971, Fax: +82-2-950-1955, E-mail: dritj@paik.ac.kr ORCID: https://orcid.org/0000-0002-8137-1633

(c) This is an Open Access article distributed under the terms of the Creative Commons Attribution Non-Commercial License (http://creativecommons.org/ licenses/by-nc/3.0) which permits unrestricted non-commercial use, distribution, and reproduction in any medium, provided the original work is properly cited. pered by the limited accessibility of the strictures and prone to complications such as tumor seeding, brush cytology is a simple and safe means of sampling biliary strictures. ${ }^{1,2}$ Brush cytology is widely available; it is performed during endoscopic retrograde cholangiopancreatography (ERCP), and the diagnostic specificity of endoscopic retrograde brush cytology (ERBC) is $100 \%$ or near $100 \%{ }^{5}$ However, its sensitivity is relatively low and variable, ranging from $18 \%$ to $80 \%{ }^{1-7}$ This may reflect the inherent properties of the tumor (its submucosal location, often fibrotic content, and inability to invade the ductal epithelium) and the extrinsic compressions leading to the stricture, which are not sampled by the brush. ${ }^{5}$ Hence, the results may be ambiguous, which confounds the treatment and management of the stricture.

Brush cytology samples are classified into four categories based on the type of cells comprising the stricture: benign, atypical, suspicious for malignancy, and malignant. Strictures 
with malignant cells are usually considered malignant and are treated as such. ${ }^{5}$ Those with atypical or suspicious cells may or may not be malignant; hence, their management is difficult and confusing, especially when biliary strictures are also indeterminate on imaging tests. ${ }^{5}$

The objective of this study was to identify the factors associated with malignant biliary strictures in patients with atypical or suspicious cells on ERBC and indeterminate biliary strictures on imaging.

\section{MATERIALS AND METHODS}

\section{Patients}

Data were collected by retrospectively reviewing the medical records of 146 consecutive patients with indeterminate biliary strictures on imaging who underwent brush cytology at the Sanggye Paik Hospital from March 2007 to December 2013. An indeterminate biliary stricture was defined as follows: (1) no identifiable mass on computed tomography (CT), transabdominal ultrasound, endoscopic ultrasound (EUS), or magnetic resonance imaging (MRI); (2) no distant metastasis on CT, transabdominal ultrasound, or MRI; and (3) no recent history ( $<3$ months) of traumatic or iatrogenic bile duct injury. A biliary stricture was diagnosed as malignant if indicated by the pathology of a biopsy or surgical specimen or the imaging findings during the follow-up period. A stricture was diagnosed as benign if indicated by the tissue sampling results and if there was no evidence of a tumor mass during a follow-up period of at least 2 years. In patients with multiple brush samples, only the samples obtained at the initial ERCP were evaluated.

Data were collected from the electronic medical records using a standardized data collection form. The final diagnosis of the disease that caused the biliary stricture was based on the integration of pathologic and cytologic results of an additional endoscopic biopsy, a fine-needle aspiration (FNA) sample, or a surgical sample during the follow up. This study was approved by the Inje University Sanggye Paik Hospital Institutional Review Board (SGPAIK 2015-12-014).

\section{Brush sampling procedure and interpretation of the results}

The cytology samples were collected by using a Microvasive Rapid Exchange cytology brush (Boston Scientific, Natick, MA, USA) with a standard 0.035 -inch guidewire. The brush sampling procedure at our institution is standardized, with brushings obtained prior to biliary dilation or biopsy. The brush was inserted into the duct of interest over the guidewire and positioned just distal to the stricture. It was then advanced from the sheath to a point proximal to the stricture and moved across the stricture in a to-and-fro manner 20 times. Lastly, it was withdrawn into the sheath and, along with the guidewire, removed from the endoscope. The brush segment of the brushing device was cut from the supporting wire, placed in ThinPrep CytoLyt solution (Cytyc Corp, Marlborough, MA, USA), and transported to the cytology laboratory.

To obtain the final cytological diagnosis, smears and precipitates from perfused saline were fixed in 95\% ethanol and stained by using Papanicolaou's method. Samples were classified as follows: no abnormal cells (benign), atypical cells, suspicious cells, or malignant cells. Patients with atypical or suspicious cells were included in our study.

\section{Study variables and definitions}

The factors studied included age; sex; smoking status; alcohol intake; body mass index; length and location of the stricture; diameter of the upstream dilated bile duct; weight loss at the time of brushing; final diagnosis and type of cancer in cases of malignancy; presence of diabetes; presence of clinical jaundice; and presence of acute cholangitis, a gallbladder stone, or a bile duct stone on CT or transabdominal ultrasound. Jaundice was defined as a serum bilirubin level $>2.0$ $\mathrm{mg} / \mathrm{dL}$. Weight loss was defined as a $\geq 10 \%$ decrease in usual body weight during the 6 months prior to brushing. Alcohol intake was defined as consumption of $>1 \operatorname{drink}(>13 \mathrm{~g}$ ) per day for at least 1 year. Laboratory parameters included serum bilirubin, aspartate aminotransferase, alanine aminotransferase, alkaline phosphatase (ALP), gamma-glutamyl transpeptidase (rGT), carcinoembryonic antigen (CEA), and carbohydrate antigen 19-9 (CA19-9) levels.

\section{Statistical analysis}

Categorical variables were analyzed by using the chi-square test or Fisher's exact test. Continuous variables, presented as mean \pm standard deviation, were analyzed by using the Mann-Whitney test. Variables in patients with malignant versus benign biliary strictures were compared via univariate analysis; this comparison was limited to patients with atypical or suspicious cells on brush cytology. Variables deemed significant in the univariate analysis were evaluated via multivariate logistic regression analysis to identify those independently associated with malignant strictures. The $95 \%$ confidence intervals (CIs) for sensitivity, specificity, positive and negative predictive values, and false negative and false positive rates were calculated. The optimal cut-off values of meaningful factors associated with malignant biliary stricture were computed by using the trade-off between sensitivity and specificity on the receiver-operating characteristic (ROC) curves, and the accuracy of prediction of the malignant stricture was estimated 
using the area under the receiver-operating curve. A $p$-value of $<0.05$ was the significance threshold for all tests. All statistical analyses were performed by using SPSS software, version 24.0 (SPSS Inc., Chicago, IL, USA).

\section{RESULTS}

\section{Overall data}

A total of 146 patients with indeterminate biliary strictures and ERBC samples were included in our study, 67 with malignant disease and 79 with benign disease. The basal characteristics of all enrolled patients are shown in Table 1. Cholangiocarcinoma (48 patients) was the most common cancer type in patients with malignant disease, followed by gallbladder cancer (six patients), pancreatic cancer (five patients), ampulla of Vater cancer (five patients), and other types (three patients). The cancer type did not significantly affect the brush cytology results. Thirty-six (53.7\%) patients with malignant disease had atypical or suspicious cells on ERBC, 12 (17.9\%) had malignant cells, and 19 (28.3\%) had no abnormal cells. In contrast, only $29(19.0 \%)$ patients with benign disease had atypical or suspicious cells and none had malignant cells (Table 2). The specimen of all patients were sufficient to be tested.

Overall, the sensitivity, specificity, positive predictive value, and negative predictive value of brush cytology for diagnosis of biliary strictures were 71.6\% (95\% CI, 59.1-81.6), 63.3\% (95\% CI, 51.6-73.6), 62.3\% (95\% CI, 51.1-72.3), and 72.5\% (95\% CI, $60.5-81.6)$, respectively. The false positive rate was $37.7 \%$ (95\% CI, 27.1-49.4), and the false negative rate was $27.5 \%$ (95\% CI, 17.8-39.8).

\section{Univariate analysis}

Patients who with atypical or suspicious cells on brush cytology were divided into two groups: those with malignant strictures and those with benign strictures. Several variables were compared between the two groups via univariate analysis during the follow-up period (Table 3). Variables that differed significantly between the groups were presence of a gallbladder stone, presence of a bile duct stone, stricture length, and levels of ALP, total bilirubin, rGT, CEA, and CA19-9.

\section{Multivariate logistic regression analysis}

On multivariate logistic regression analysis, the independent predictors of a malignant stricture were as follows: elevated CA19-9 level (odds ratio [OR], 3.49; 95\% CI, 1.24-9.81; $p=0.018$ ), elevated CEA level (OR, 4.90; 95\% CI, 1.69-14.22; $p=0.003$ ), elevated ALP level (OR, 3.36; 95\% CI, 1.20-9.36; $p=0.02$ ), elevated rGT level (OR, 4.31; 95\% CI, 1.52-12.26; $p=0.006$ ), and long strictures (OR 5.25, 95\% CI 1.80-15.29;
Table 1. Basal Characteristics of the 146 Patients in Our Study

\begin{tabular}{|c|c|}
\hline Variable, $n(\%)$ & Value \\
\hline Male gender & $86(58.9)$ \\
\hline Age $(y r$, mean $\pm S D)$ & $66.9 \pm 12.6$ \\
\hline $\mathrm{BMI}\left(\mathrm{kg} / \mathrm{m}^{2}\right.$, mean $\left.\pm \mathrm{SD}\right)$ & $22.5 \pm 2.9$ \\
\hline Diabetes mellitus & $32(21.9)$ \\
\hline Smokers & $31(21.2)$ \\
\hline Alcoholic & $47(32.2)$ \\
\hline \multicolumn{2}{|l|}{ Clinical presentations } \\
\hline $\mathrm{GB} / \mathrm{CBD}$ stone & $69(47.3)$ \\
\hline Cholangitis & $100(68.5)$ \\
\hline Jaundice & $98(67.1)$ \\
\hline Weight loss & $25(17.1)$ \\
\hline \multicolumn{2}{|l|}{ Laboratory values (mean $\pm \mathrm{SD})$} \\
\hline $\operatorname{AST}(\mathrm{U} / \mathrm{L})$ & $169.9 \pm 223.3$ \\
\hline $\operatorname{ALT}(\mathrm{U} / \mathrm{L})$ & $174.6 \pm 218.3$ \\
\hline $\operatorname{ALP}(\mathrm{U} / \mathrm{L})$ & $312.0 \pm 295.4$ \\
\hline Total bilirubin (mg/dL) & $6.1 \pm 7.0$ \\
\hline rGT (U/L) & $437.4 \pm 422.8$ \\
\hline CEA (ng/mL) & $2.6 \pm 4.0$ \\
\hline CA19-9 (U/mL) & $1,219.2 \pm 2,800.2$ \\
\hline Elevated CA19-9 (>37 U/mL) & $85(58.2)$ \\
\hline Length of stricture $(\mathrm{mm}$, mean $\pm \mathrm{SD})$ & $19.8 \pm 15.7$ \\
\hline \multicolumn{2}{|l|}{ Location of stricture } \\
\hline Upper third & $81(55.5)$ \\
\hline Middle third & $35(24.0)$ \\
\hline Lower third & $30(20.5)$ \\
\hline \multicolumn{2}{|l|}{ Final diagnosis } \\
\hline Benign stricture & $79(54.1)$ \\
\hline Pancreatic cancer & $5(3.4)$ \\
\hline Cholangiocarcinoma & $48(32.9)$ \\
\hline AOV cancer & $5(3.4)$ \\
\hline GB cancer & $6(4.1)$ \\
\hline Others & $3(2.1)$ \\
\hline Detection of cancer & $67(45.9)$ \\
\hline
\end{tabular}

ALP, alkaline phosphatase; ALT, alanine aminotransferase; AOV, ampulla of Vater; AST, aspartate aminotransferase; BMI, body mass index; CA19-9, carbohydrate antigen 19-9; CBD, common bile duct; CEA, carcinoembryonic antigen; GB, gallbladder; rGT, gamma-glutamyl transpeptidase; SD, standard deviation.

$p=0.002$ ) (Table 4). The ROCs for the independent predictors of malignant stricture (CA19-9, CEA, ALP, rGT, and length of stricture) are shown in Fig. 1. On the basis of the highest sensitivity and specificity values generated from the ROC, we generated the optimal cut-off values of each factors for pre- 
dicting the malignancy (Table 5).

\section{DISCUSSION}

Benign and malignant diseases of the biliary tract can cause

Table 2. Brush Cytology Results

\begin{tabular}{lcc}
\hline & Benign $(\boldsymbol{n}=\mathbf{7 9})$ & Malignant $(\boldsymbol{n = 6 7 )}$ \\
\hline No abnormal cells $(n, \%)$ & $50(63.3)$ & $19(28.3)$ \\
Atypical cells $(n, \%)$ & $25(31.6)$ & $20(29.9)$ \\
Suspicious cells $(n, \%)$ & $4(5.1)$ & $16(23.9)$ \\
Malignant cells $(n, \%)$ & $0(0)$ & $12(17.9)$ \\
Sensitivity & $71.6 \%(95 \%$ CI, 59.1-81.6) \\
Specificity & $63.3 \%(95 \%$ CI, 51.6-73.6) \\
Positive predictive value & $62.3 \%(95 \%$ CI, 51.1-72.3) \\
Negative predictive value & $72.5 \%(95 \%$ CI, 60.5-81.6) \\
\hline
\end{tabular}

$\mathrm{CI}$, confidence interval. biliary strictures and, in turn, cholangitis and jaundice. ${ }^{1,2,-9}$ Most biliary strictures can be identified via imaging modalities such as CT, ultrasound, and MRI, with additional information provided by EUS for less prominent strictures. ${ }^{5,10-14}$ However, strictures are difficult to diagnose if there is no definite causative lesion such as a mass, a stone, or inflammation. ${ }^{5}$ Brush cytology during ERCP is an established technique for evaluating biliary strictures. ${ }^{3,8,15}$ It has a relatively high specificity but a low and broad-range sensitivity. ${ }^{5}$ In particular, because of desmoplastic reactions or fibrosis, which are common in pancreatobiliary malignancies, it is unclear whether strictures with atypical or suspicious cells on brush cytology are malignant. ${ }^{5}$ When such strictures are also indeterminate on imaging, it is also unclear what additional diagnostic tests are required and how long and at what intervals follow-up examinations should be performed.

EUS-FNA is an alternative technique for pathological diagnosis of biliary strictures. ${ }^{10,16}$ However, the results are operator-dependent and targeting is difficult when strictures are

Table 3. Univariate Comparisons between Benign and Malignant Biliary Strictures in Patients with Atypical or Suspicious Cells on Brush Cytology

\begin{tabular}{|c|c|c|c|}
\hline & Benign $(n=29)$ & Malignant $(n=36)$ & $p$-value \\
\hline Gender (male, \%) & $14(48.3)$ & $24(66.7)$ & 0.107 \\
\hline Age $(y r$, mean \pm SD) & $66.76 \pm 17.09$ & $69.86 \pm 11.81$ & 0.391 \\
\hline Jaundice $(n, \%)$ & $20(69.0)$ & $30(83.3)$ & 0.142 \\
\hline Cholangitis $(n, \%)$ & $23(79.3)$ & $21(58.3)$ & 0.109 \\
\hline Weight loss $(n, \%)$ & $4(13.8)$ & $8(22.2)$ & 0.294 \\
\hline BMI $\left(\mathrm{kg} / \mathrm{m}^{2}\right)$ & $21.69 \pm 3.05$ & $23.07 \pm 2.70$ & 0.057 \\
\hline GB stone $(n, \%)$ & $14(48.3)$ & $4(11.1)$ & 0.002 \\
\hline BD stone $(n, \%)$ & $18(62.1)$ & $3(8.3)$ & 0.000 \\
\hline Alcohol $(n, \%)$ & $11(37.9)$ & $10(27.8)$ & 0.273 \\
\hline Smoking $(n, \%)$ & $3(10.3)$ & $7(19.4)$ & 0.256 \\
\hline Diabetes mellitus ( $n, \%)$ & $4(13.8)$ & $9(25.0)$ & 0.210 \\
\hline \multicolumn{4}{|l|}{ Laboratory values (mean \pm SD) } \\
\hline AST (U/L) & $202.97 \pm 166.90$ & $158.72 \pm 144.16$ & 0.256 \\
\hline $\operatorname{ALT}(\mathrm{U} / \mathrm{L})$ & $202.41 \pm 189.82$ & $169.38 \pm 153.09$ & 0.448 \\
\hline $\operatorname{ALP}(\mathrm{U} / \mathrm{L})$ & $231.45 \pm 163.68$ & $411.75 \pm 285.57$ & 0.004 \\
\hline total bilirubin $(\mathrm{mg} / \mathrm{dL})$ & $3.23 \pm 2.29$ & $8.70 \pm 8.48$ & 0.001 \\
\hline rGT ( U/L) & $312.91 \pm 271.02$ & $596.72 \pm 527.17$ & 0.011 \\
\hline CEA (ng/mL) & $1.49 \pm 1.78$ & $3.96 \pm 5.34$ & 0.017 \\
\hline CA19-9 (U/mL) & $91.02 \pm 272.22$ & $1,682 \pm 3,155.64$ & 0.005 \\
\hline Length of stricture (mm, mean \pm SD) & $14.86 \pm 14.83$ & $25.83 \pm 15.33$ & 0.005 \\
\hline Location of stricture (lower/mid/upper, \%) & $10.3 / 31.0 / 58.6$ & $27.8 / 25.0 / 47.2$ & 0.145 \\
\hline Upstream bile duct diameter $(\mathrm{mm}$, mean $\pm \mathrm{SD})$ & $11.0 \pm 3.5$ & $13.0 \pm 4.3$ & 0.449 \\
\hline
\end{tabular}

ALP, alkaline phosphatase; ALT, alanine aminotransferase; AST, aspartate aminotransferase; BD, bile duct; BMI, body mass index; CA19-9, carbohydrate antigen 19-9; CEA, carcinoembryonic antigen; GB, gallbladder; rGT, gamma-glutamyl transpeptidase; SD, standard deviation. 
Table 4. Variables Associated with Malignant Strictures

\begin{tabular}{lccc}
\hline & Odds ratio & $\mathbf{9 5 \%}$ CI & $\boldsymbol{p}$-value \\
\hline GB stone & 0.134 & $0.038-0.477$ & 0.002 \\
BD stone & 0.056 & $0.014-0.225$ & 0.000 \\
CA19-9 & 3.492 & $1.242-9.815$ & 0.018 \\
CEA & 4.909 & $1.694-14.224$ & 0.003 \\
t.Bil & 2.506 & $0.918-6.842$ & 0.073 \\
ALP & 3.362 & $1.207-9.361$ & 0.020 \\
rGT & 4.318 & $1.521-12.262$ & 0.006 \\
Length of stricture & 5.250 & $1.802-15.294$ & 0.002 \\
\hline
\end{tabular}

ALP, alkaline phosphatase; $\mathrm{BD}$, bile duct; CA19-9, carbohydrate antigen 19-9; CEA, carcinoembryonic antigen; CI, confidence interval; GB, gallbladder; rGT, gamma-glutamyl transpeptidase; t.Bil, total bilirubin. small. ${ }^{1,2}$ Moreover, when strictures are malignant, there is the possibility of tumor seeding via the needle tract. ${ }^{1}$ Therefore, identification of the factors associated with malignant strictures would facilitate diagnosis and allow us to follow patients at high risk. In the study by Navaneethan et al., the presence of clinical jaundice, current alcohol consumption, and an elevated CA19-9 level $(>33 \mathrm{U} / \mathrm{mL})$ at the time of ERBC independently predicted an increased risk of cancer during the follow-up period in patients with atypical cells. ${ }^{5}$

According to our data, the diagnostic sensitivity of brush cytology in the 146 patients enrolled in this study was $71.6 \%$, which is similar to previously published values (18\% to $80 \%)$, whereas the specificity was lower than in other studies $(63.3 \%$ versus nearly $100 \%$ ). The difference in the sensitivity values may reflect the inclusion of patients with atypical or suspi-
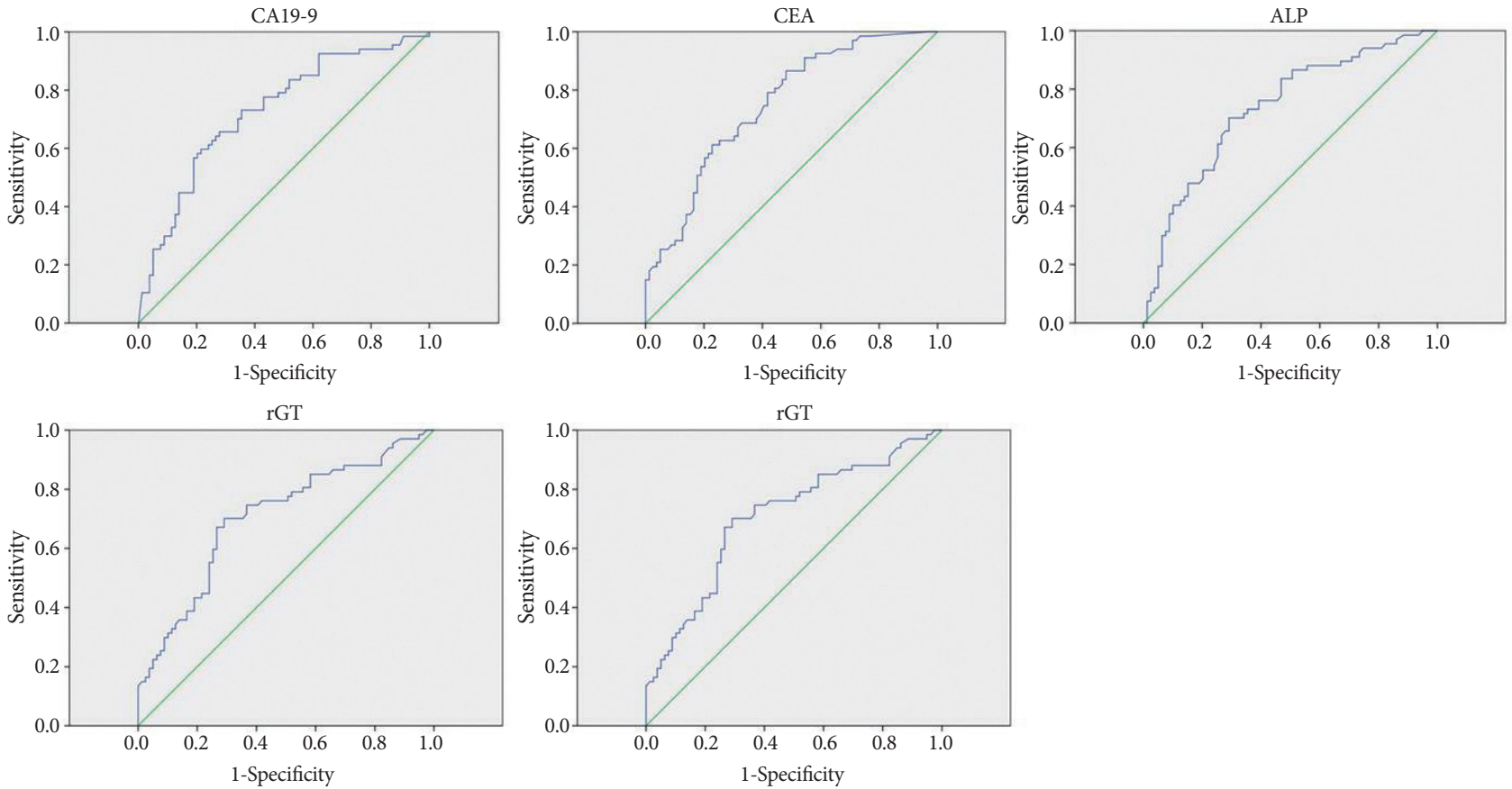

Fig. 1. Receiver operator curves and corresponding area under curves for carbohydrate antigen 19-9 (CA19-9), carcinoembryonic antigen (CEA), alkaline phosphatase (ALP), gamma-glutamyl transpeptidase ( $\mathrm{rGT}$ ) and length of stricture.

Table 5. The Optimal Cut-Off Values of CA19-9, CEA, ALP, rGT and Length of Stricture

\begin{tabular}{lccccc}
\hline & AUC $(\mathbf{9 5} \% \mathbf{C I})$ & Cut-off value & Sensitivity & Specificity & $\boldsymbol{p}$-value \\
\hline CA19-9 & $0.729(0.649-0.811)$ & $56.44 \mathrm{U} / \mathrm{mL}$ & $73.1 \%$ & $64.6 \%$ & 0.000 \\
CEA & $0.750(0.673-0.828)$ & $1.51 \mathrm{ng} / \mathrm{mL}$ & $79.1 \%$ & $58.7 \%$ & 0.000 \\
ALP & $0.736(0.654-0.817)$ & $200.5 \mathrm{U} / \mathrm{L}$ & $76.1 \%$ & $60.8 \%$ & 0.000 \\
rGT & $0.706(0.620-0.791)$ & $297.0 \mathrm{U} / \mathrm{L}$ & $74.6 \%$ & $63.3 \%$ & 0.000 \\
Length of stricture & $0.791(0.717-0.865)$ & $14.5 \mathrm{~mm}$ & $74.6 \%$ & $74.7 \%$ & 0.000 \\
\hline
\end{tabular}

ALP, alkaline phosphatase; AUC, area under curve; CA19-9, carbohydrate antigen 19-9; CEA, carcinoembryonic antigen; CI, confidence interval; rGT, gamma-glutamyl transpeptidase. 
cious cells as well as malignant cells in our study.

Factors that differed significantly in patients with malignant versus benign biliary strictures in our univariate analysis were presence of a gallbladder stone, presence of a bile duct stone, a long stricture, and elevated ALP, total bilirubin, rGT, CEA, and CA19-9 levels. Among these, stricture length was the strongest independent predictor of malignancy in our multivariate analysis (OR, 5.3; 95\% CI, 1.8-15.3; $p=0.002$ ). According to Park et al., extrahepatic cholangiocarcinomas have an infiltrative growth pattern, and thus it is necessary to distinguish them from benign strictures. ${ }^{13}$ Factors facilitating differentiation include the margin (irregular or smooth), symmetry (symmetric or asymmetric), and shape (abrupt or gradual narrowing). ${ }^{13}$ Notably, Park et al. found that the malignant and benign strictures differed significantly in length. ${ }^{13}$

Elevated levels of CA19-9, CEA, ALP, and rGT were also independently associated with malignant strictures in our multivariate analysis. CA19-9 is a well-known, helpful biomarker for pancreatobiliary cancer and its prognosis. ${ }^{17-19}$ However, CA19-9 levels may stay normal in early or localized cancers and increased in benign diseases such as cholangitis and choledocholithiasis. ${ }^{17,19}$ CEA is a well-establisheed biomarker for gastrointestinal tract and pulmonary cancer, as well as a prognostic factor for cholangiocarcinoma. ${ }^{18}$ As reported by $\mathrm{Li}$ et al., co-detection of CEA and alpha-fetoprotein or CA 125 is more diagnostically accurate than detection of CA19-9 alone. ${ }^{18}$

ALP resides in hepatic sinusoidal and biliary canalicular membranes and is overexpressed in cholestatic diseases. ${ }^{20} \mathrm{Sev}$ eral studies have shown that patients with malignant strictures or cholangiocarcinomas have higher levels of ALP than those with benign biliary diseases such as gallstones. ${ }^{20}$ This finding dovetails with our results identifying ALP as a diagnostic marker for malignant biliary strictures. As an explanation for the association between ALP levels and malignant strictures, we note that biliary duct obstructions due to malignant strictures tend to be more complete and prolonged than those due to benign causes, such as biliary stones (in which the size of the obstructions fluctuates owing to the movement of the stone). ${ }^{21}$

rGT is normally present in the membranes of liver, bile duct, lung, pancreas, brain, gallbladder, and kidney tissues and heart muscles. ${ }^{22}$ Why rGT levels are increased in malignant strictures is not known; however, we suggest the progressive and chronic changes associated with cancerogenesis result in severe biliary dysfunction. ${ }^{22}$

We also identified gallbladder stones (OR, 0.1; 95\% CI, $0.0-0.5 ; p=0.002$ ) and bile duct stones (OR, $0.1 ; 95 \%$ CI, 0.0-0.2; $p=0.000$ ) as negative predictive factors for malignant biliary strictures. Owing to inflammation, a stricture is more likely to be benign when a stone is present.
Our study has two limitations: its retrospective design and its small number of patients. Patient number was limited by the performance of the study at a single center and the exclusion of patients who died from other causes during the study period or who were followed up at other hospitals. Despite these limitations, our study is valuable because it is one of only a few previous studies on indeterminate biliary strictures on imaging and atypical or suspicious cells on brush cytology.

The appropriate management and follow-up strategies for patients with atypical or suspicious cells on brush cytology and indeterminate biliary strictures on imaging have not yet been determined. Identification of markers for malignant biliary strictures will facilitate diagnoses in these patients, hence ensuring proper management and eliminating unnecessary and sometimes costly follow-up procedures.

\section{Conflicts of Interest}

The authors have no financial conflicts of interest.

\section{REFERENCES}

1. Mahmoudi N, Enns R, Amar J, AlAli J, Lam E, Telford J. Biliary brush cytology: factors associated with positive yields on biliary brush cytology. World J Gastroenterol 2008;14:569-573.

2. Tanaka H, Matsusaki S, Baba Y, et al. Usefulness of endoscopic transpapillary tissue sampling for malignant biliary strictures and predictive factors of diagnostic accuracy. Clin Endosc 2018;51:174-180.

3. Parsi MA, Deepinder F, Lopez R, Stevens T, Dodig M, Zuccaro G. Factors affecting the yield of brush cytology for the diagnosis of pancreatic and biliary cancers. Pancreas 2011;40:52-54.

4. Kawada N, Uehara H, Katayama K, et al. Combined brush cytology and stent placement in a single session for presumed malignant biliary stricture. J Gastroenterol Hepatol 2011;26:1247-1251.

5. Navaneethan U, Singh T, Gutierrez NG, et al. Predictors for detection of cancer in patients with indeterminate biliary stricture and atypical cells on endoscopic retrograde brush cytology. J Dig Dis 2014;15:268-275.

6. Navaneethan U, Njei B, Lourdusamy V, Konjeti R, Vargo JJ, Parsi MA. Comparative effectiveness of biliary brush cytology and intraductal biopsy for detection of malignant biliary strictures: a systematic review and meta-analysis. Gastrointest Endosc 2015;81:168-176.

7. Victor DW, Sherman S, Karakan T, Khashab MA. Current endoscopic approach to indeterminate biliary strictures. World J Gastroenterol 2012;18:6197-6205.

8. Lee HJ, Cho KB. Diagnosis of malignant biliary stricture: more is better. Clin Endosc 2018;51:115-117.

9. Temiño López-Jurado R, Cacho Acosta G, Argüelles Pintos M, Rodríguez Caravaca G, Lledó Navarro JL, Fernández Rodríguez C. Diagnostic yield of brush cytology for biliary stenosis during ERCP. Rev Esp Enferm Dig 2009;101:385-389, 390-394.

10. Papachristou GI, Smyrk TC, Baron TH. Endoscopic retrograde cholangiopancreatography tissue sampling: when and how? Clin Gastroenterol Hepatol 2007;5:783-790.

11. Ohshima Y, Yasuda I, Kawakami H, et al. EUS-FNA for suspected malignant biliary strictures after negative endoscopic transpapillary brush cytology and forceps biopsy. J Gastroenterol 2011;46:921-928.

12. Fritcher EG, Kipp BR, Halling KC, et al. A multivariable model using advanced cytologic methods for the evaluation of indeterminate pan- 
creatobiliary strictures. Gastroenterology 2009;136:2180-2186.

13. Park MS, Kim TK, Kim KW, et al. Differentiation of extrahepatic bile duct cholangiocarcinoma from benign stricture: findings at MRCP versus ERCP. Radiology 2004;233:234-240.

14. Baron TH, Harewood GC, Rumalla A, et al. A prospective comparison of digital image analysis and routine cytology for the identification of malignancy in biliary tract strictures. Clin Gastroenterol Hepatol 2004;2:214-219.

15. Stewart CJ, Mills PR, Carter R, et al. Brush cytology in the assessment of pancreatico-biliary strictures: a review of 406 cases. J Clin Pathol 2001;54:449-455.

16. DeWitt J, Misra VL, Leblanc JK, McHenry L, Sherman S. EUS-guided FNA of proximal biliary strictures after negative ERCP brush cytology results. Gastrointest Endosc 2006;64:325-333.

17. Liang B, Zhong L, He Q, et al. Diagnostic accuracy of serum CA19-9 in patients with cholangiocarcinoma: a systematic review and meta-analy- sis. Med Sci Monit 2015;21:3555-3563.

18. Li Y, Li DJ, Chen J, et al. Application of joint detection of AFP, CA19-9, CA125 and CEA in identification and diagnosis of cholangiocarcinoma. Asian Pac J Cancer Prev 2015;16:3451-3455.

19. Qin XL, Wang ZR, Shi JS, Lu M, Wang L, He QR. Utility of serum CA19-9 in diagnosis of cholangiocarcinoma: in comparison with CEA. World J Gastroenterol 2004;10:427-432.

20. Zare M, Kargar S, Akhondi M, Mirshamsi MH. Role of liver function enzymes in diagnosis of choledocholithiasis in biliary colic patients. Acta Med Iran 2011;49:663-666.

21. Hayat JO, Loew CJ, Asrress KN, McIntyre AS, Gorard DA. Contrasting liver function test patterns in obstructive jaundice due to biliary strictures [corrected] and stones. QJM 2005;98:35-40.

22. Goldberg DM. Structural, functional, and clinical aspects of gamma-glutamyltransferase. CRC Crit Rev Clin Lab Sci 1980;12:1-58. 